\title{
A Contrastive Study of Genric Organization of thesis Discussion Section Written by Iranian MA Students in the Field of TEFL and chemistry
}

\author{
Khosro Soleimani \\ Islamic Azad University, Ravansar, Iran \\ Email:khosrosol@yahoo.com \\ *Habib Soleimani \\ Department of English Language and literature, University of Kurdistan, Sanandaj, Iran \\ h.soleimani@uok.ac.ir/h181352@gmail.com
}

\section{Doi:10.5901/mjss.2015.v6n3s1p206}

\begin{abstract}
The purpose of this study was to see whether there were any significant differences in type and frequency of occurrence moves in theses discussion sections written by Iranian MA students in TEFL and MSc students in chemistry and to find a common pattern of schematic move structure for each field using Hopkin and Dudley - Evans' (1988)model. To this end, 60 theses discussion sections were selected. 30 discussion sections were from different state universities of Iran in TEFL and 30 from chemistry theses discussion section of Razi university of Kermansha. The data collected from each field was analyzed and moves were identified and compared. Chi square tests were run to verify whether the differences were significant or not. The results of the analysis revealed that although a new move type was detected that was not present in Hopkin and Dudley Evans' model, there were no significant differences in terms of type and frequency in most cases. The results also indicated that, despite low discrepancies between the common patterns of the two fields, they generally tended to follow Hopkin and DudleyEvans' model. This demonstrated that all graduate students tried to orient themselves to structure of theses through reading and imitating MA theses. This may imply that in order to enhance students' awareness in relation to discussion section of theses, their awareness regarding generic structure of moves be raised.
\end{abstract}

Keywords: Moves, Discussion section, Genre

\section{Introduction}

The word genre has been important in literacy and language education in recent years particularly concerning the teaching of writing. The teaching of academic literacy (John, 1997) and teaching of English for academic purposes (Swales, 1990; Bhatia, 1993) are examples of areas which have drawn on the concept of genre. Different scholars have presented different definitions for term genre.

Holmes (1997:322) defines genre as" a class of texts characterized by specific communicative functions that tend to produce distinctive structural patterns". Bhatia (1997) states that genres:

Are meant to serve the goals of specific discourse communities, and in so doing, they tend to establish relatively stable structural forms and, to some extent, even constrain the lexico- grammatical resources in expressing these forms .(p.176) Swales (1990:58) has provided a working definition of genre: "A genre comprises a class of communicative events the members of which share some set of communicative purposes. These purposes are recognized by the expert members of the parent discourse community, and thereby constitute the rationale for genre. This rationale shapes the schematic structure of discourse and influences and constrains choice of content and style.

An important characteristic of genre, asserted by many genre scholars from language teaching perspective is that each genre includes a number of elements called moves (Swales, 1990). The basic building blocks and functional units of analysis in most genre analysis studies are moves.

A move is defined as segment of text that is shaped and constrained by specific communicative function, that is, every move is subservient to the communicative purpose of genre. Within generic structure some moves are obligatory and some are optional. Obligatory moves are necessary to achieve the communicative purpose of genre, optional moves are selected to add to effectiveness of communication and do not change the communicative purpose of text (Henry and Rosebury, 1998). 
Since no established criterion is offered in literature to discriminate move from each other, there has been controversy among genre scholar ideas concerning move boundaries. Dudley- Evans (1994:226) puts that move discrimination should be made on the basis of three criteria "linguistic evidence, comprehension of the text, and understanding the expectations that both general academic community and particular academic community have of the text".

During the recent years, there has been a considerable interest in genre based analysis of different sorts of texts.

The main motive for the emergence and development of "genre analysis" in ESP context was to increase the degree of awareness of the students to different texts, especially academic texts, in order to enhance non-native students' ability in both understanding and producing academic texts efficiently. Therefore, there has been an enthusiasm among ESP practitioners for further exploration in academic text. So far, the focus of genre analysis has been mostly on academic genres and in particular on research articles and textbooks. In addition, different subgenres of these genres have been analyzed such as abstract, introduction, discussion and other sections. However little analysis has been done on the texts of dissertation and thesis, due to difficulty of obtaining texts from university libraries (Atkinson, 1997) and considering sheer size of theses and dissertation as a text for analysis (Swales and Thompson, 1999). The focus in this study is on these genres. By investigating the structure of specific types of text and schematic move structure, teachers and students gain clearer idea of end product.

There are substantial literatures in this regard, Swales and Feak (1994) analyzed different research articles conclusion sections. According to their findings, the conclusion section is composed of three moves:

1. Move 1 is a conclusion of research findings and is usually quite extensive

2. Move 2 discusses the implications of research

3. Move 3 discusses the possibilities in the future research.

Hewings (1993b) also analyzed conclusion section of Master of business administration dissertations and noticed that they contained three extensive and recognizable parts a) to report b) to comment and c) to suggest.

Ruiying and Allison (2003) conducted a genre analysis on Result and conclusion sections of research articles in the field of applied linguistics. They examined the way in which research articles report empirical investigations in applied linguistics. Their analysis concerns the rhetorical choices among possible Results, Results and Discussion, discussion, Conclusion, and Pedagogic Implications section, and identifies specific organizational choices within each section. They find each the dominant moves and steps of each section separately and the relation of these sections to one another. The analysis of four sections provides evidence that they can overlap, although they differ primarily in their communicative functions and are used by different headings. The findings show that due to overlap of rhetorical functions, the structure of empirical RAs in applied linguistics are more flexible in concluding sections, but they differ in emphasis across RA sections.

Brett (1994) examined the result section of 20 sociology RAs. He reported that this section is the place where new findings are not only highlighted but also interpreted and commented upon by authors. Holmes (1997) examined discussion sections of social science research articles. The analysis has been done based on modified version of moves, communicative categories, provided by Hopkin and Dudley - Evans (1988) with 11 move schemes to analyze the Result section of RAs. He examined 30 research articles in three fields of history, political science and sociology. The findings showed that although, there exists fundamental similarities to the natural sciences, the discussion section of social science articles has specific features that should be taken into account for developing academic writing and reading materials . He found no move "completely obligatory" in his corpus; the commonest moves were deduction and statement of result. He notes that moves tend to occur in predictable order and also in cycle. There was some interdisciplinary variation - there were more moves and move cycle in political science RAs, and fewer in history.

Moreover, in 2001, Holmes researched 43 Agricultural Economics RAs. The commonest moves were statement of result (in 100 percent of RAs), deduction (94 percent), recommendation (79 percent) and background information (60 percent). Peacock (2002) using Dudley - Evans' (1994) model analyzed communicative moves in discussion sections across seven disciplines. A number of marked interdisciplinary differences were found in type and number of moves and move cycles.

Hopkins and Dudley - Evans (1988) did a move analysis on the discussion section of medical research articles. They found one move - statement of result - as an obligatory move. As Lewin and Fine (1996:424) agree and assert no one has clearly described the rhetorical work needed in discussion section as well as Paltridge comments, students often have difficulty in meeting the demands of the kind of writing required of them at this particular level(Paltridge,1997:61).In addition, the situation becomes more complicated with the fast growing numbers of non-native graduate students in the fields of science and technology. Further, large numbers of students are undertaking degrees throughout the world where they are required to write their theses in English even in country like Iran in some disciplines particularly chemistry in Razi 
university of Kermanshah. Hence, as a contribution to the academic writing in Iranian academic centers specially, MA students in the fields of chemistry and TEFL, and to help Iranian ESP learners to face the challenge of writing dissertation, this study intends to find out to what extent the move structures of thesis discussion in chemistry and applied linguistics are identical or different and find schematic pattern of organization of thesis discussion for these fields. An awareness of schematic pattern of organization, absence and presence of such differences and similarities will help us in English for academic purposes (EAP) as well as in teaching non-native students to write acceptable thesis.

EAP originates in an intention to identify and teach the language and literacy skills that students need to know to succeed in university and in disciplinary context. Since writing thesis is difficult for native students and so for non-natives (Paltridge,2002), and also Iranian university students in other disciplines except TEFL have passed few courses in English and their writing is an underdeveloped skill, familiarity with academic writing and its conventions is essential for them to write their thesis acceptably.

This study focuses on discussion section because it is the section that students have the greatest difficulties with, due to interpretation and contextualization of results. Also supervisors and students attach the great importance to this section (Dudley-Evans, 1993; 1994). Since in Iran there is no research in the realm of dissertation genre and it's subgenre like discussion section to find schematic pattern of organization in chemistry and applied linguistic fields, this study is significant. Chemistry was selected since in Iran except from applied linguistics only in this field students are required to write their theses in English.

\section{Methodology}

In order to conduct this research, 60 thesis discussion sections were selected. 30 discussion sections were from TEFL and 30 from chemistry fields. Then each text was analyzed separately and carefully and moves of each text were extracted on the basis of Hopkin and Dudely-Evahs, (1988) model. To establish reliability of recognized moves, an intercoder procedure was utilized. It means another researcher who was familiar with the concept of move analysis was asked to analyze texts and extract the moves and for chemistry also a specialist informant was asked to help extract the moves.

After long discussions, raters reached agreement. In addition, phi coefficient value $\% 83$ shows the reliability of the analysis. In order to find possible differences between discussion sections of these two fields, moves were compared and two models (one model for chemistry and one for TEFL) were obtained on the basis of Hopkin and Dudely-Evans' model. Then the frequency of occurrence of each move with their percentages was measured and Chi-square test was run to see whether differences were significant or not.

To clarify the stages of move analysis the Hopkin and Dudley- Evan's model is presented below,

Hopkins and Dudley- Evan's model

(1) Information move: the writers present background information about theory. The aim of the research, the methodology used, and previous research that is felt to be necessary for understanding of what follows in the move cycle.

(2) Statement of results: this is frequently the first move in a cycle and is followed by one or more moves that comment on the results. A statement of the result either presents a numerical value or refers to a graph or table of results.

(3) (Un) expected outcome: the writers make a comment an the fact that a result is expected or, much more frequently, unexpected or surprising. the fact that the result is unexpected or surprising creates a need for a comment.

(4) Reference to previous research (comparison): the writers either compare their results with those found in previous research.

(5) Explanation of unsatisfactory result: the writers give reasons for an unexpected result or one that differs significantly from previous research.

(6) Exemplification: the writer gives an example to support his /her explanation.

(7) Claim: the writers make a generalization arising from their results which is their contribution to the ongoing research on the topic. This is often referred to as a knowledge claim. This may be a hypothesis, which is a hedged claim, and a deduction, which is a more confidently presented (i.e. unhedged) claim. Claims tend to be presented cautiously, that is using modal or other hedged phrases.

(8) Reference to previous research (support): the writer quotes previous work to support his or her deduction or hypothesis.

(9) Recommendations: the writers make suggestions for future lines of research on the topic, or for improvements in the methodology followed in the research reported in the article. 
(10) Justification: the writer justifies the need for future work recommended.

\section{Results}

The purpose of this study was to see whether there were any significant differences in type and frequency of occurrence of moves in thesis discussion sections written by Iranian MA students in TEFL and MSc students in chemistry and to find a common pattern of schematic move structure in this section of theses written in each field.

The analysis began with a frequency count of each move followed by Chi square test run to check the significance of the differences in frequency. The results and findings are presented move by move.

Information move (move one)

As it is shown in table 1, this move occurred in $80 \%$ percent of applied linguistic theses and $93.3 \%$ percent of chemistry theses.

The Chi square test results presented in table 1 show that Chi square observed value $\left(X^{2}=2.308\right)$ at .05 with degree of freedom of 1 is less than the critical value $\left(x^{2}=3.84147\right)$, which indicates that the difference is not statistically significant.

Statement of results (move two):

In their study, Hopkins and Dudley- Evans found it as an obligatory move that occurred with considerable frequency. In the present study this move occurred in 100\% percent of applied linguistics and all of chemistry student's texts. (See table 1). As the frequency of occurrence of moves was the same in the two fields, no difference can be observed.

Unexpected outcome (move three)

As it was observed in the corpus, none of applied linguistic and chemistry students used this move.

Reference to previous research (move four)

The frequency table shows that $50 \%$ percent of applied linguistic students and $20 \%$ percent of chemistry students used this move (table 1).

As the results presented in table 1 show, since the observed statistics $\left(X^{2}=5.934\right)$ at .05 with degree of freedom of 1 exceeds the critical value $\left(x^{2}=3.8417\right)$, the difference in using this move is statistically significant.

Explanation (move five):

Since the theses analyzed seemed to have no surprising or unsatisfactory result, both applied linguistics and chemistry students skipped this move in the cycle too.

Exemplification (move six)

As it is shown in table 1, this move occurred in 10 percent of chemistry student texts and none of applied linguistics texts. As the frequency of this move is very low in both groups, it is not viable to test the differences.

Claim (move seven):

As in the present study the percentage of this move in the data of both groups was the same (20\% percent) (see table 1), so the no difference obviates the use of Chi square.

Reference to previous research (support) (move eight)

This move appeared in none of chemistry theses and only in $10 \%$ of applied linguistics theses (table 1).Since the frequency of occurrence of this move is very low in both disciplines, it is not viable to test the significance of differences.

Recommendation (move nine)

Table 1 depicts that none of applied linguistic students and $10 \%$ of chemistry students utilized this move in their theses.

As the frequency of this move is very low in both groups, it is not viable to test the differences.

Justification (move ten) 1).

It was found that this move occurred in none of the applied linguistics and chemistry discussion section texts (table 
Table 1. Frequencies and percentages of discussion moves in TEFL and chemistry and Observed statistics value

\begin{tabular}{cccccc}
\hline Moves & \multicolumn{2}{c}{ Frequency } & \multicolumn{2}{c}{ Percentage } & Observed value \\
\hline & TEFL & Chemistry & TEFL & Chemistry & $\chi^{2}$ \\
\hline 1 & 24 & 28 & 80 & 93.3 & 2.308 \\
\hline 2 & 30 & 30 & 100 & 100 & \\
\hline 3 & 16 & 22 & 53.3 & 73.3 & \\
\hline 4 & 15 & 6 & 50 & 20 & \\
\hline 5 & 0 & 3 & 0 & 10 & \\
\hline 6 & 6 & 6 & 20 & 20 & \\
\hline 7 & 3 & 0 & 10 & 0 & \\
\hline 8 & 0 & 3 & 0 & 10 & \\
\hline
\end{tabular}

By investigating Iranian applied linguistics and chemistry discussion section of theses, in terms of Hopkin and Dudley Evan's (1988) model a new move was detected that was not present in Hopkin and Dudley - Evans' scheme. This is called "explanation of the result". Here the writer suggests the reasons for the result .In all papers this move occurred after "statement of the result" move. It occurred in 53. 3 percent of applied linguistic discussion section and 73.3 percent of chemistry texts as represented in table $2 \mathrm{~A}$.

As it is shown in table $2 \mathrm{~B}$, the Chi square observed value $\left(X^{2}=2.584\right)$ at .05 with degree of freedom of 1 is less than critical value $\left(X^{2}=3.84147\right)$, which indicates that there is no statistically significant difference in using this move between chemistry and applied linguistic students.

Table 2. The new move obtained in the data

\begin{tabular}{ccc}
\hline Field & Frequency & Percentage \\
\hline Applied linguistic & 16 & 53.3 \\
\hline chemistry & 22 & 73.3 \\
\hline
\end{tabular}

Table 3. The new move obtained in the data

\begin{tabular}{cl}
\hline$X^{2}$ & df \\
\hline 2.584 & 1 \\
\hline
\end{tabular}

In terms of common pattern of schematic move structure in thesis discussion section, in TEFL and chemistry, it was found that there are some differences between Hopkins and Dudley -Evans' (1988) model and the model found out in this study. In this model a somewhat different sequence of moves and a new move type was detected. We first present the pattern which is common among the graduate students and then the pattern specific to each field is presented.

Here the new model is presented as follows which includes the main options available to MA, MSc students in TEFL and chemistry, it should be born out that the list is not exhaustive:

1. Information move, in which the writer presents background information about theory, the aim of the research and the methodology used.

2. Statement of the result, in which the writer comments on the result.

3. Explanation of result, in which the writer gives the reasons for the result irrespective of whether the result is expected or not expected.

4. Reference to previous research, in which the writer compares his or her result with those reported in literature.

5. Exemplification, in which the writer gives an example to support his or her explanation.

6. Claim, in which the writer makes a generalization arising from particular results which contributes to ongoing research on the topic. This may be a hypothesis or a deduction.

7. Reference to previous research (for support), in which the writer quotes previous work to support his or her deduction or hypothesis

8. Recommendation, in which the writer makes suggestions for future work.

Table 3 shows the frequency and percentages of moves for graduate students in TEFL and chemistry. It also shows which moves are obligatory or not, based on Hyland (2003) suggestion that over sixty percent, the move is considered obligatory. 
Table 3. Frequencies and percentages of discussion moves in TEFL and chemistry and obligatory and optional moves model

\begin{tabular}{ccccccccc}
\hline Moves & \multicolumn{2}{c}{ Frequency } & \multicolumn{2}{c}{ Percentage } & \multicolumn{2}{c}{ Obligatory } & \multicolumn{2}{c}{ Optional } \\
\hline & TEFL & Chemistry & TEFL & Chemistry & TEFL & Chemistry & TEFL & Chemistry \\
\hline 1 & 24 & 28 & 80 & 93.3 & ${ }^{*}$ & ${ }^{*}$ & & \\
\hline 2 & 30 & 30 & 100 & 100 & ${ }^{*}$ & ${ }^{*}$ & & \\
\hline 3 & 16 & 22 & 53.3 & 73.3 & & & & \\
\hline 4 & 15 & 6 & 50 & 20 & & & ${ }^{*}$ & ${ }^{*}$ \\
\hline 5 & 0 & 3 & 0 & 10 & & ${ }^{*}$ & ${ }^{*}$ & ${ }^{*}$ \\
\hline 6 & 6 & 6 & 20 & 20 & & & ${ }^{*}$ & ${ }^{*}$ \\
\hline 7 & 3 & 0 & 10 & 0 & & & ${ }^{*}$ & ${ }^{*}$ \\
\hline 8 & 0 & 3 & 0 & 10 & & & & \\
\hline
\end{tabular}

As it can be understood from this table, in spite of the similarities between the two groups in the use of moves and their frequencies, some differences can be observed.

In terms of similarities, as table 3 depicts, 24 students in TEFL and 28 in chemistry used the "information move", i.e. it occurred in $80 \%$ of TEFL and $93.3 \%$ of chemistry theses discussion section. So this move is obligatory for both groups. Both groups were similar in terms of the use of move two, which was the most frequent move used by both groups. Again Move three, "explanation of the result", which was the move added by the researcher, there was no difference between the two groups. As the table shows this move was used by $53.3 \%$ percent of TEFL students whereas $73 \%$ percent of chemistry students. The difference is not statistically significant and seems to be obligatory move for both groups. Move six, claim, was used by both groups equally.

In terms of differences, move four, reference to previous research, was utilized in $50 \%$ percent of TEFL texts and $20 \%$ percent of chemistry discussions showing a significant difference between the two groups.

The table shows that move five "exemplification" was used by none of TEFL students and only three chemistry students. Move seven, reference to previous research was absent in the chemistry corpus and $10 \%$ percent of TEFL students used this move. Move eight, recommendation, was utilized by none of the TEFL students while $10 \%$ percent of chemistry students used this move.

These differences suggest two different common patterns of schematic move structure for the two different fields. What follows is the presentation of the models suggested for TEFL and chemistry based on raw frequencies.

Applied linguistic discussion model

1. Information move

2. Statement of result

3. Explanation of the result

4. Reference to previous research (comparison)

5. Claim

6. Reference to previous research (support)

Chemistry discussion section model

1. Information move

2. Statement of the result

3. Explanation of the result

4. Reference to previous research

5. Exemplification

6. Claim

7. Recommendation

It should be mentioned that the starred moves were used with very low frequencies by one of the groups and so the differences could not be tested statistically. We have included them in these models based on their raw frequencies.

\section{Discussion}

The first part of the purpose of this study addressed the differences between the kind and frequency of moves used in the discussion section of theses in TEFL and chemistry using Hopkin and Dudley Evan's (1988) model. The data analysis of move structure of discussion section theses in TEFL and chemistry revealed some differences between move structure of 
thesis discussion section written by Iranian students in the fields of TEFL and chemistry in terms of type and frequency although the differences were not statistically significant in most cases.

As data analysis showed "information move " was reflected in both groups and seemed to be obligatory for both groups .Move two "statement of result" occurred in both groups and it was also obligatory move for both groups. It is consistent with Hopkin and Dudley -Evans' study which revealed that in the discussion section of articles and dissertations, there was only one obligatory move, that is, "statement of result".

Regarding move five "reference to previous research for comparison", TEFL students made more frequent use of this move compared to chemistry students. As it was observed there was statistically significant difference in using this move between the two different disciplines. This may be due to the fact that science writers spend much more time explaining their results than referring to the results of other researchers. In TEFL, it is more common linking their results with previous research. It is consistent with the findings of Peacock (2002) on communicative moves in discussion sections across seven disciplines, revealing that referring to previous research was more common among language and linguistic students than science students. It also diverges from Hyland's suggestion (1998 b: 449) that science authors typically build on and refer back to prior research.

The move "exemplification" was used by chemistry students only. Accordingly, "reference to previous research for support" was used only by TEFL students. Since the frequency of occurrence of these moves were very low, it is difficult to justify the result. Move ten "recommendation" was absent in TEFL corpus which may be because there is a section in their theses called "suggestions for further study." However there were few instances of reference to the improvement of methodology in chemistry discipline. With this very few instances we can hardly make comments on this result. However, it might be argued that science students in this field tend to avoid suggesting something that they themselves would like to continue at the post-graduate. This is might be the reason why they do not make suggestions for further study.

Regarding the common pattern of schematic move structure in theses discussion sections, some of the moves (unexpected outcome, explanation of unexpected outcome, justification) proposed by Hopkin and Dudley- Evans (1988) model did not appear in the corpus. Move three "unexpected outcome" was absent in the corpus. This may be due to nature of research, in chemistry, in a context like Iran, where students tend to do replication research which enables them to predict the results. It goes without saying that predicted results leaves no space for unexpected outcomes. The same argument can be applied to TEFL students. Furthermore students in this level have access to very limited resources and facilities and limited time to complete their studies, so they tend to replicate research and select topics for their studies which would come to definite result very quickly.

As "unexpected outcome " move was not present in the corpus, no "explanation of unexpected outcome" was observed. In addition, "justification" move occurred in none of chemistry and TEFL discussion section texts. This move depends on move "recommendation", since no suggestions for future work was observed, this move was also absent in the corpus. Some moves like moves "exemplification", "reference to previous research for support" and "recommendation" were used only in one corpus with very low frequency of occurrence. With very low frequency, the result is not dependable because in a bigger corpus we might find instances of these moves in the other corpus. Future research might enable us to comment on these moves.

An interesting result was the identification a move called "explanation of the result". It was found in both TEFL and chemistry discussion texts and seemed to be obligatory in chemistry field. The point to be discussed here is that although in Dudley -Evans' model there is a move called "explanation of unsatisfactory result" the obtained move is to some extent different because it first immediately follows the move "statement of the result", second it is used irrespective of whether the result is expected or not expected. The result can be justified by Pecock's (2002) revised model of Hopkins and Dudley - Evans, in which the expected and unexpected outcome moves are considered the elements of the same move.

In spite of very low discrepancies between the common pattern of the two disciplines, they generally follow Hopkin and Dudley-Evans' model. This can be attributed to the fact that MA students follow models of others who have already completed their theses. In other words the discussion section of theses may follow the same pattern because all graduate students try to orient themselves to the structure of theses through reading MA theses and imitating their structure. This fact is also confirmed by Hyland (2003) who confirm that students look at each other's dissertations to get an idea of the structure, content and expression.

As imitation is too highly individual and takes time, raising awareness in relation to different sections of theses especially the discussion section might be very helpful for MA students.

The findings of this study provide an approach to describing the organization of particular kinds of texts and explicit description of the way in which texts are organized, that is helpful for teachers and students alike. It can add to our understanding of genre conventions in academic writing in the sense that it offers them models that provide a means whereby students could analyze the effectiveness of their own writing and that of others and help them to discover how 
writers organize texts thus provide a useful framework for teachers and students alike.

It also helps ESP teachers and course designers to prepare discipline - specific writing courses. It may also contribute to the field of syllabus design in a sense that production of appropriate and relevant materials and syllabi for ESL, ESP and EAP writing courses require an awareness of genres. Lack of awareness of the concept of genre in academic discourse leads to inadequate materials and syllabi (Holmes, 1997). So it is important for syllabus designer to be familiar with the concept of genre to provide appropriate and relevant materials for writing course and also include subjects as move structure of different sections of articles and dissertations since students can follow common patterns that result in flexible thinking and informed creativity. In addition, as stated by Dudley- Evans (1997: 351- 352) teaching the subject through a focus on moves is the best approach.

\section{References}

Atkinson, D. (1997). Teaching and researching the thesis / dissertation in ESP. Colloguium introduction, TESOL, 97. Orlando, FL.

Bhatia, V.K. (1993). Analyzing Genre: Language use in Professional Settings. London: Longman.

Bhatia, V. K., and Tay. M.(eds) (1987). The teaching of English in meeting the needs of business and technology. Vol 1 and 2. The Report of the UNDP Government of Singapore, Department of English Language and Literature: National University of Singapore.

Brett, P., (1994). A genre analysis of the results section of sociology articles. English for Specific Purpose, 13, 47- 59.

Dudley-Evans, T. (1986). Genre analysis: an investigation of the introduction and discussion sections of MSc. dissertations. In M. Coulthard, talking about text. Birmingham, UK: English Language Research, Birmingham University.

Dudley- Evans, T. (Ed) (1987). Genre analysis and ESP. English Language Research journal, 1.

Dudley-Evans, T. (1994). Genre analysis: an approach to text analysis for ESP. In: Coulthard, M. (Ed), Advances in written text Analysis. Routledge, London, 219-228.

Dudley - Evans, T. (1997). Genre: how far can we should go? World Englishes, 16 (3), 351 - 358.

Hewings, M. (1993). How to conclude a discussion. In: G.M. Blue (ed). Language, Learning and Success: Studying through English. London: Modern English publications and the British Council, 105 - 112.

Holmes, R. (1997). Genre analysis and the social sciences: an investigation of structure of research article discussion sections in three disciplines. English for Specific Purposes, 16(4), 321-337.

Holmes, R. (2001). Variation and text structure: The discussion section in economics research articles. ITL Review of Applied linguistics, $131-132,107-135$.

Hopkins, A., and Dudley-Evans, T. (1988). A genre-based investigation of discussion sections in articles and dissertations. English for Specific Purposes, 7, 113-122.

Hyland, K. (1992). Genre analysis: just another fad. Forum, 30(2), 14-17.

Hyland, K. (1998). Persuasion and context: the pragmatics of academic metadiscourse. Journal of Pragmatics, 30, 437 - 455.

Hyland, K. (2002).Genre: Language, Context and Literary. Annual Applied linguistics, 13(3), 85-92.

Hyland, K. (2003). (Graduate gratitude: the genre structure of dissertation acknowledge. English for Specific Purposes, 20,242-268.

John, A. (1990). Coherence as a cultural phenomenon: employing ethnographic principles in the academic milieu. Cambridge: Cambridge University Press.

Lewin, B.A., and Fine, G. (1996). The writing of research texts: genre analysis and its applications. In: Rijlaarsdam, G., Vanden Bergh, H., Couzijn, M. (Eds). Theories, Models and Methodology in Writing Research. Amsterdam University Press, Amsterdam, 423444..

Paltridge, B. (1995). Working with genre: a pragmatic perspective. Journal of Pragmatics, 24(14), 393 - 404.

Peacock, M. (2002). Communicative moves in the discussion section of research articles. System, 30, 479-497.

Ruiying, Y., \& Alison, D. (2003). Research articles in applied linguistics: moving from results to conclusions. English for Specific Purposes, 22, 365- 385.

Swales, j. M. (1981a). Aspects of article introductions (Aston ESP Reports No.1). The Language Studies Unit. The University of Aston in Birmingham, Birmingham, UK.

Swales, j. M. (1984). Research into the structure of introductions to journal articles and its application to the teaching of academic writing; In: R. Williams, J. Swales and J. Kirkman (Eds), Common ground: shared interests in ESP and communication studies. ELT Documents, 117.

Swales, J. M. (1990). Genre Analysis: English in academic and research settings. Cambridge: Cambridge University Press.

Swales, J. M. and Feak, C. B. (1994). Academic writing for graduate students. University of Michigan Press. Ann Arbor. 